\title{
Only Connect: discovery pathways, library explorations and the information adventure
}

\section{Book review}

Walsh, A. and Coonan, E. (2013) Only Connect: discovery pathways, library explorations and the information adventure. Huddersfield: Innovative Libraries, pp.239, 978-099576652-1-7.

\section{Overview}

A novel concept for the world of publishing in this field, Only Connect has been produced primarily as an electronic book to incorporate multimedia resources. Initial viewing of the printed version proved somewhat disconcerting due to the lack of an index and the 'chapter chooser' which encourages a non-linear engagement with the book. However, after reading the introduction, this becomes completely logical as there is no sense of a clear progression between chapters. This book has been designed around a range of interpretations and experiences of information literacy (IL) from a number of perspectives. The chapter chooser recommends starting to read at any point and navigating in any order. In fact, the only theme that links these chapters is that of a form of information literacy.

The first part of the book 'mapmakers' explores tried and tested methods of teaching and learning IL with discussions of the role of the library and librarians. The second part of the book, a section called 'travellers', appears more abstract. It looks at some creative and reflective journeys where the authors happen upon an element of IL on their travels. These examples draw on external media to illustrate their creative discoveries, so the printed book alone does not do justice to the essence of the collection of chapters. The frequent use of the incorporated pertinent online sources makes it clear that a poor written imitation or mere description within the text would not be appropriate. 
The intended audience is anyone who teaches anything to do with $\mathrm{IL}$ as there are suggested strategies, but also anyone attempting to learn the key principles. Examples of students going through the process offer reassurances that any difficulties they may face are shared with others. In addition to this more academic readership, the publication is likely to be appreciated by people in creative fields across the arts to get a sense of how their work can be applied to IL.

From simple strategies which are usable in the classroom using creatures and games, to complex theories, such as psychoanalysis and Vygotsky's scaffolding, applied to a range of settings, this book will provide something for everyone.

What sets this book apart from many others written about IL is that it does not offer a precise definition, in fact it discourages this by developing the idea that IL is contextual, offering 'complementary yet deeply contrasting visions of the information journeys'. It validates the multiple definitions and brings together applications embracing very different perspectives. In contrast with many texts on the market, this one can certainly not be accused of offering IL for a specific purpose.

Although the chapters are very different from each other, a number of recurring themes emerge from the publication which are summarised briefly below in no particular order.

\section{Technology}

Engaging with students through the use of mobile voting systems is touched upon within a Prezi presentation, and online this comes with the freedom of navigating to more information outside of the IL concept if desired. The incorporation of YouTube, audio files and Prezi materials throughout provides an additional perspective to many authors' assertions, whilst Amado and Alarcónis focus on how technology itself has helped their research and art. 


\section{Identity}

How information builds our identities and understanding of the world is a recurring topic throughout the text. Burkhardt and Carbery explore how information can construct one's own image from students' use of information to construct an identity, but also how an identity can be reflected back at them from a social media perspective. A sense of changing identity is also discussed by Osborne who focuses on the growing amount and range of supporting and educational information available to young homosexuals over the years. He also raises the question of whether information reflects society's attitudes or creates them.

\section{Librarians and library spaces}

Different views of librarians and library spaces are given. There is the librarian as a partner in the learning process (Cullen and Delasalle), reflections of experiences and struggles library users may have in finding information in such an established system as a library (Norton and Ramsden), plus the Sorceress librarian as a mentor in the quest for information.

\section{Tried and tested methods}

Exercises to evaluate (Walton) and synthesise sources (Gröppel-Wegener) are offered as a different way to engage students in these tasks. There is also an account of a specific step by step worked example of research from Cullen and Delasalle which raises important considerations for keyword searching on a database from the student's viewpoint.

\section{Analogies}

In order to make some concepts new and exciting and approach them from a different angle, as well as possibly to make a point inoffensively, an interesting collection of analogies is presented. Examples of these range from the hero's journey to classic fairy tales, and it is difficult to forget the librarian as a sorceress or masquerading as a bear. 


\section{Students}

The importance of engaging students in critical conversations, exploring their assumptions and guiding them through a process of IL is discussed, alongside academics learning the process and linking it to their own discipline (Dimmock, Hoon and Maclellan, and Johnson and Walsh). The student voice is also acknowledged.

\section{Disability}

Observations from individuals with additional needs are explored from multiple perspectives. In addition to 'solutions' for the world to implement to make their lives easier, documented examples of how they have navigated IL themselves are offered (Andrews and Soulsby-Kermode, Norton).

\section{Reflection and personal discovery}

Personal discoveries and journeys feature in most sections of Walsh and Coonan's collected works. These include disability diagnoses, literature searching and a 'reflection of a reflection' observation in a practice based setting (Mathew).

\section{Final thoughts}

In terms of the aims of the book - only one is provided overtly. That is, to bring together a range of interpretations and perspectives on the idea of information literacy, and this was achieved well. Far more limitations and notions of what will not be offered throughout the book were given. There has been much debate in recent years about what IL actually constitutes, and this collection of experiences and observations can change your opinion with every section. As an 18 year old entering university for the first time (many years ago), this would have confused me and not helped me to understand what was expected of me when engaging with the library and research processes.

Through this text (or anarcho-narrative unbook as described in the introduction) readers can discover that there is no right way to 'do' information literacy and it also acknowledges 
that students do not fit into pigeon holes we may devise for their learning. Having said that, and despite first impressions, it is not actually solely for librarians, students and tutors in higher education; there are plenty of examples of how IL can operate outside of universities.

Publishing primarily as an electronic book is ideal for this as it reflects the nature of the technology used by the contributing authors, no doubt alongside other impressive research projects. The process of accessing the book online is in itself an exercise in IL for the reader/browser. The content within the printed text is of course valuable, but it is clearly limited in scope.

It summarises and extends new debates on the topic well. However, material comes from a range of disciplines which interpret and present IL so differently from each other in style and approach that it is not always easy to navigate from one to the next. If you are prepared for this challenge and interested in how others approach it, it is easy to take yourself out of your traditional comfort zones with some of the interpretations of the subject.

\section{Reviewer}

Helena Beeson worked for over ten years as an Academic Librarian at the University of Northampton and for the last two years has since been working as an Academic Practice Tutor based in the library. 